\title{
CORRELATION OF OVARIAN HISTOLOGY AND IN- TERSEXUALITY OF THE GENITAL APPARATUS, WITH SPECIAL REFERENCE TO APL-TREATED INFANTILE RATS ${ }^{1}$ \\ LORE MARX ${ }^{2}$ AND J. T. BRADBURY \\ Department of Gynecclogy and Obstetrics, University of Michigan \\ Medical Sohool, Ann Arbor \\ TWO PLA'TES (FTFTEEN FIGURES)
}

Masculinization of infantile female rats treated with gonadotropic extracts from pregnancy urine and pregnant mare serum has been reported previously (Bradbury and Gaensbauer, '39). This effect was mediated through the ovary, since it did not occur in rats which had been oophorectomized before the treatment was started. ${ }^{3}$ In case reports of virilism in women, tubular structures or male Leydig cells are sometimes regarded as the cause of the abnormality. But since small amounts of heterosexual hormone occur in normal individuals, it is entirely possible that cases of excessive heterosexual secretion result from hypertrophy of one of the normal components of the gonad rather than from the presence of hermaphroditic elements. It is the purpose of the present study to evaluate the stimulation of the male and female genital apparatus in the experimental rats, and then to determine the histological changes in the ovary which are associated with the production of sufficient androgenic substance to produce definite masculinization. The evaluation of the effects of male and female hormone is not as easy in infantile as in adult rats, for in the postembryonal stage the

* Aided by a grant from the Horace H. Rackham School of Graduate Studies to the Department of Obstetrics and Gynecology.

2 Supported by an Aaron Mendelson Fund.

${ }^{3}$ Since the above report, the adrenals of another series of rats were examined and no hypertrophy of the cortex nor $x$ zone was found. 
genital apparatus is still incomplete and both sex hormones exert a morphogenetic influence similar in several respects (Raynaud, '38 b, Greene, Burrill and Ivy, '39). In our study of sex hormones we found that the clitoris, the epithelium of the prostate, and a ridge on the uterus reacted specifically to androgens. The formation of acini on a rudimentary mammary duct system was a consistent finding in masculinized animals. Vaginal cornification, and extension of the mammary ducts, on the other hand, proved to be reliable indicators for estrogen. Vaginal growth, rupture of the vaginal membrane, enlargement of the uterus are ambiguous responses which cannot be ascribed to one or the other sex hormone.

\section{CONTROL MATERIAL}

Female rats possess several homologues of the male reproductive apparatus. They have a thin perforated clitoris and sometimes a corpus cavernosum urethra. A cartilaginous anlage of the penis bone is said to be present in the newborn female (Greene and Burrill, '39) but was not found in our sectioned material of infantile rats. The glans is vestigial and covered on its dorsal surface by a short epithelial ingrowth which does not delaminate to form a preputial space. Both sexes have preputial glands which are small during infantile age and grow large in adult rats, especially in the male. Prostate tissue is occasionally present in female rats. Its functional differentiation is a good indicator of androgens except in infantile animals. Witschi, Mahoney and Riley ('38) described active prostates in 25 day old females and castrates, and Price ('37) found that the activity of the prostate transplanted from the infantile male was preserved longer in pregnant than in non-pregnant female hosts. In one of six controls in which the upper urethra was sectioned a prostate was found. It was from a 31 day old female and was almost inactive.

A deep furrow constricts the ovary near the attachments of the suspensory ligament and of the fimbria of the oviduct. Around this cleft primordial follicles are massed together in 
a tissue of very small cells as in the neogenic zone of the embryonic ovary. Peripherally from this area the primordial follicles become less numerous. Strands of follicles are often found growing from the focus at the suspensory ligament into the cortex and they may also radiate from the attachment of the fimbria. Primary follicles make up the bulk of very young ovaries, since stroma is scarce and interstitial tissue usually absent. As later follicular stages appear, they acquire a thin theca. The young theca is fibrous, but later is composed of small pale epithelial cells with an indistinct border (fig. 1). The nuclei in the epithelial theca are dark and small, round or polygonal. In 20 day old rats, wheel cells (absence of nuclear membrane and coarse chromatin clumps around the periphery) are prevalent; the cytoplasm appears foamy, yet the cell contours are still indistinct. Graafian follicles develop early but remain small. Mitoses are fairly numerous, especially in the granulosa.

Ovaries of prepuberal females contain large follicles and definite interstitium. Figure 2 is a section through the ovary of a 31 day old rat. In many follicles the granulosa has undergone degeneration with formation of basophile droplets, in others only the cumulus has disintegrated. Ovocytes lying free in the antrum tend to divide, so that multiple ovocytes are frequently seen. The interstitial cells are small (fig. 3), especially in peripheral areas extending down from the germinal epithelium. Occasionally the interstitium and less frequently the theca enclose areas of initial luteinization where the cells are larger and have spongy eosinophilic cytoplasm. The nuclei are large and turgid, their chromatin arranged along a fine framework. In the granulosa there are also rare areas foreshadowing luteinization in 31 and 37 day old animals. The cells there show neither degeneration nor full transformation; they are large and pale, the nucleus often long and pointed.

In the mature ovary, although the theca around follicles and eysts may remain luteinized, the theca surrounding a corpus luteum reverts to a thin fibrous sheath as shown in 
figure 10. Primary follicles are decreased in number in luteinized ovaries as described by Allen ('23).

Products of the first proliferation are preserved in the rat ovary. Postnatally most of the tubules are in the hilus region and have made connection with the rete, but a few usually persist within the cortex at the proliferation focus or beneath it along the suspensory ligament and may be continuous with the rete. Rete and Wolffian body are well developed. In rare instances eosinophile tissue with minute nuclei grows into the lumina and in pregnant adults the tubulae become surrounded by dense stroma.

\section{EXPERIMENTAL OBSERVATIONS}

To facilitate treatment and to maintain uniform nutritional conditions, suckling females were selected in groups of eight and placed with a foster mother. Gonadotropic hormones were injected daily starting with the sixth day of age. The series treated with sex hormones were started on the eighth day of age and injected on alternate days.

Anterior pituitary-like substances. In the study of APL (anterior pituitary-like) substance, 160 females have been injected for various lengths of time with 2,5 , or $10 \mathrm{RU}$ daily. For the most part the urinary preparations used in this study had been obtained for another investigation (Gaensbauer and Bradbury, '39). The rat unit dosages listed were the luteinizing units of Antuitrin $\mathbf{S}$ and Follutein. All preparations were diluted so that the respective dose was given in 0.1 cc. fluid. At least two treated rats and controls of the same age were sacrificed at frequent intervals in the earlier stages of treatment and the genital apparatus was fixed for histological preparation. Mammary glands were fixed in formalin and stained and mounted in toto.

Any of the chosen doses of APL produced vaginal patency between the sixteenth and twenty-second day of age. During the injection of 2 units, irregular vaginal cycles were observed. In four of eight rats treated with 5 units permanent estrus became established at the time of vaginal rupture or 
a little later; and all the rats injected with 10 units stayed in the estric phase throughout the period of treatment. There was a slight stimulation of acinar growth in the mamma and the vagina hypertrophied.

Masculinization as evidenced by a marked hypertrophy of the clitoris occurred in all but two treated litters. It was first recognized at the age of 10 days and became more pronounced with continued treatment. The glans clitoridis enlarged and could be exposed by retracting the well developed prepuce. Horny spicula were very prominent on the surface of the glans and a cartilage with early ossification was present. In a few animals the uterus hypertrophied; in some cases a peculiar ridge developed along its medial surface. This ridge contained large blood vessels and smooth muscle and possibly it is homologous to the gubernaculum Hunteri. The upper urethra of twelve treated infantile rats was sectioned and a rather small but active prostate was found in one of them. The animal was 34 days old and had received twenty injections of two RU APL.

The ovaries were somewhat larger than in controls except in prepuberal animals. The ovaries of thirteen infantile rats and five rats around the normal age of puberty were examined histologically. In infantile rats the follicles had reached the same stage of development as in untreated animals of the same age, but were decreased in number. At 34 days, (fig. 6) there were a few abnormally large follicles which had become cystic. In younger rats the effect of the treatment became histologically recognizable only in the wide spacing of the follicles, the interval being filled with the broad thecal zone. Figure 5 shows large theca cells. A considerable amount of interstitium was present in rats older than 34 days (fig. 4). Theca and interstitium consist of small, epithelial cells as in controls (compare fig. 4 with fig. 3). With higher doses (10 units daily) extensive luteinization of theca and interstitium had taken place by the thiry-first day of age. Mitoses were somewhat more numerous in the theca of the experimental animals than in the controls. 
Interstitial tissue appeared between 15 and 23 days, which was earlier than in controls. It is postulated that the interstitium may arise in two ways, either as a remainder from the theca of degenerated follicles or by the proliferation of strands of anovular follicles from the germinal epithelium. (Brambell, Parkes and Fielding, '27 c) report a third way, namely a transformation of the granulosa of mice in which the germinal epithelium had been inactivated by the application of x-rays.) The arrangement of the interstitium in our experimental rats makes it appear that the main portion had originated from the theca of atretic follicles. Most of the interstitium formed masses in the deeper layers of the ovary rather than strands growing down from the surface. The formation of interstitium from the germinal epithelium would be a sterile proliferation, but actually in treated animals ovogenesis was greatly increased (fig. 7).

The first signs of luteinization were occasionally seen in rats younger than 23 days. The cells of theca and interstitium were still small, but the cytoplasm appeared foamy and the cell borders were visible. The nuclei remained small, but their chromatin was more dispersed. With age, the lutein structure became more pronounced, but the luteinized tissue was restricted to small areas. The theca around cystic follicles of 34 day rats was thin but markedly luteinized. In degenerating follicles the basement membrane disappeared and theca and granulosa interdigitated as shown in figure 8. Where the theca consisted of luteinized cells, their size, spongy cosinophile cytoplasm and vesicular nucleus made it possible to distinguish them from the small clear granulosa cells with nuclei rich in chromatin. But often there was a more intermediate cell type of which it was impossible to say whether it was derived from the granulosa or belonged to a part of the theca not yet luteinized. In such cases the boundary between theca and granulosa could not be determined. In two 34 day old rats treated with 2 units daily, the granulosa of a few follicles was partially luteinized and a third animal had small, solid regressing corpora which may have arisen from the granulosa. The rat with excessive proliferation of primary follicles (fig. 7) showed no luteinization.

Four rats injected with 5 or 10 units daily from the sixth day on were killed between the forty-first and fifty-first days of age. The fresh weight of the ovaries was more than twice normal (48 and $52 \mathrm{mg}$.) in the rats treated with 5 units, 
and about seven times normal (115 and $150 \mathrm{mg}$.) in the animals injected with 10 units. Histologically the ovaries were characterized by the advanced luteinization. Fully luteinized cells of the theca (fig. 9) and granulosa (fig. 12) look alike. It is possible to determine the origin of the lutein tissue only in young corpora since the early stages of corpora lutea derived from the granulosa have radial septa and in the central cavity an organized coagulum. Theca lutein tissue is less regular in form and surrounds the remainder of a follicle. The abnormal condition of simultaneous luteinization in theca and granulosa was realized in a rat treated with the lower dose, from which figures 9 and 12 have been taken. Theca and interstitium occupied as much space as cystic follicles and granulosa corpora. The ovaries of two other rats, one treated with 5 and one with 10 units, contained numerous theca corpora and a few solid corpora the origin of which is doubtful. In the rat treated with 10 units the lutein cells were especially large (compare fig. 13 with fig. 12). The fourth rat, treated with 10 units, had presumably also been lacking in corpora lutea derived from the granulosa for it had furnished estric smears over a long period of time. But when, on the second day of diestrus after 29 days of estrus, the ovaries were removed, they had the mulberry form peculiar to late pregnancy. The ovaries consisted mainly of numerous large, newly formed corpora lutea and a few large cysts arranged around a center of connective tissue. Radial septa in the lutein tissue and an organized coagulum in the central cavity of the corpora proved their origin from the granulosa. There was little interstitium left in the ovary. Intermediate stages of follicle development were rare in all puberal ovaries, but there was a moderate number of primary follicles under the germinal epithelium. Theca and what remained of active granulosa contained many mitotic figures, but they were less frequent in the interstitium. The mulberry ovary possessed most mitoses and here, in smaller number, they were even found in the corpora lutea. 
The stimulation of rete and Wolffian body has not been studied sufficiently to make any generalizations. It was noted that intratubular tissue was found more frequently and abundantly in treated rats, and in the two puberal rats treated with 10 units daily there was a prominent connective tissue sheath.

Continuation of treatment beyond the age of puberty maintained persistent estrus and stimulation of the female reproductive organs. In a 79 day old rat injected with $10 \mathrm{RU}$ daily, full mammary development was noted besides the hypertrophy of the other female and male genitals. The ovaries weighed $185 \mathrm{mg}$. The parenchyma consisted of corpora and a very large cyst, and there was little interstitium. Likewise the theca was in a fibrous or epithelial state. Primary and intermediate stages of follicles were present in good number. Few mitoses were seen in the granulosa and none in theca or interstitium. The tubes of the Wolffian body were very large and enclosed much intratubular tissue.

Discontinuation of treatment shortly before the normal age of puberty permitted temporary recovery, if 5 units or less had been injected daily. A rat injected with $2-5$ units daily between the sixth and thirty-sixth day of age still exhibited hyperplasia of the genitals on the forty-fourth day, but the ovaries were not unusually large. They contained follicles of all stages and solid corpora lutea. Interstitium was not prominent and had reverted to the epithelial stage. The theca was thin and mostly fibrous as in normal mature rats with corpora. There were many mitoses in the granulosa, few in the theca and none in the interstitium.

Normal ovarian function did not last, as shown by vaginal smears. Samples taken from nine rats starting the seventh week after cessation of treatment with $2 \mathrm{RU}$ showed moderate disturbance of the cycle. From 5 to 8 months later the seven surviving animals were in persistent estrus. Four of eight rats injected with 5 units and all rats injected with 10 units continued in permanent estrus after the treatment was stopped. Ovaries of adult rats in permanent estrus always had many follicles but no corpora lutea. 
The experimental material treated with gonadotrops other than chorionic hormone is not extensive, but will permit comparison of the different agents. All preparations cause precocious maturity, but their late effect on the genitalia is different. At the end of injections of human chorionic factor, only ovaries and vagina were consistently hypertrophic in young rats, while pregnant mare serum and to a lesser degree pituitary extract induced uterine hyperplasia as well. Masculinization, on the other hand, occurred only under the influence of chorionic factor or mare serum extract. This difference seems to be only a quantitative one, since Guyénot and NavilleTrolliet ('36) found that pituitary extract would masculinize guinea pigs as well as anterior pituitary-like substance.

Mare serum hormone. The mare serum preparation used was Gonadogen, Upjohn. A unit of this preparation given in three daily injections will raise the weight of the infantile rat ovary to $65 \mathrm{mg}$., that is four to six times the normal weight. One-half unit was injected daily into sixteen rats from the sixth to the thirty-first day.

The mare serum hormone was the most potent of the gonadotropic preparations tested, It produced the earliest rupture of the vaginal membrane and excessive hypertrophy of the ovaries and secondary female and male organs. By the fourteenth day the vagina was open in all rats and thereafter the smear varied. The genital hyperplasia showed individual variations. Those rats in which the ovarian enlargement was extreme, also had the largest female and male genitals. Uterus, vagina and the acini of the mammary glands were fully developed. The duct system of the mamma was not stimulated, but the acini were well formed. A ridge was prominent along the antimesometrial surface of the uterine horns. The clitoris became more penis-like than after injection of chorionic material. The ovaries and upper urethrae were examined histologically in three rats and in one of these, a 23 day old rat, a large prostate was found fully as active as the prostate of a female rat injected with testosterone. 
The ovaries exhibited prouounced follicle stimulation and luteinization. Two pairs were recovered on the twenty-third day of age. In one pair the ovaries were as large as the kidneys of the animal (after fixation still $8 \mathrm{~mm}$. long) while in the other animal, the ovaries were of approximately the same size as in a mature rat (after fixation $4 \mathrm{~mm}$. long). Histologically the latter ovaries were not too different from the organs of rats treated with the chorionic factor, as theca and interstitium were prominent. But there were also cystic Graafian follicles and, unlike to the condition prevailing in chorion hormone treated rats, theca and interstitium (fig. 11) were luteinized. Even the granulosa included a few spots of incipient transformation. Theca and granulosa were extremely actively proliferating. Around the cleft near the oviduct a small amount of embryonal tissue was present. The huge ovaries were composed of big, thin-walled cysts. There was no interstitium. Granulosa and ovocyte were well preserved, but there were no signs of granulosa luteinization. The basal membrane of the granulosa was lacking in many instances so that the small cells were in contact with the luteinized theca cells. In a few follicles with small antra the theca had grown thick and had become highly luteinized, forming corpora around a small cavity. Young follicles were scarce and the primary follicles opposite the tube were scattered under the germinal epithelium; there was no solid mass of neogenic tissue. Long strands under the germinal epithelium which arose near the proliferation center were probably germinal cords homologous to seminiferous tubules. Mitoses were frequent in these tubules, in the granulosa and the theca of the follicles. But the high number of mitoses in the former animal was not reached.

The ovaries of the last rat, sacrificed at 43 days, that is around the normal age of puberty, were heavily luteinized. One layer of follicles surrounded a core of corpora. The majority of the follicles was solid with thick granulosa, but there were also some rather small Graafian follicles. Most of the follicles and corpora had a thin fibrous theca. The 
interstitium between them had very small cells in which the nuclear chromatin was condensed in coarse lumps, but at places theca and interstitium were luteinized. Mitoses were rare except in the granulosa of certain follicles. Clusters of primary follicles and some fine germinal cords with light cytoplasm surrounded the ovarian cleft. The parovarium was rather large and, like the rete, well differentiated.

Seven months after discontinuation of treatment, vaginal smears revealed that five of the eight surviving animals were in persistent estrus.

Gonadotropic pituitary extract. Prephysin, Chappell was employed. The amount producing an increase in ovarian weight of 50-100\% if given in three daily injections to infantile rats is termed a rat unit.

Sixteen rats were injected with 5 units daily from the sixth until the twenty-fifth day. In six animals the vagina opened on the sixteenth day; by the twenty-third day all were patent. Vaginal smears indicated irregular cycles. Two rats were sacrificed on the twenty-second day, one had an enlarged vagina, glans clitoridis and preputial glands, otherwise the genitals were infantile in both. In four animals sacrificed 9 days after cessation of treatment, at the age of 34 days, the uteri remained infantile. One rat had large ovaries (after fixation $7 \mathrm{~mm}$. long), and in this and another one there was a moderate enlargement of vagina, clitoris and preputial glands and a stimulation of duct and acinar system in the mammary gland. Three rats were examined histologically and no prostate was found.

Ovarian sections of the two 22 day old rats were similar to sections from the chorion hormone series. The hyperplastic theca and interstitium occupied about half the ovary in one rat and a far greater portion in the other one. The latter was the rat with some development of the male organs. The two animals differed also in the degree of theca luteinization; the interstitium was largely luteinized in both of them. Figure 14 shows the differentiation of the less hyperplastic theca. Mitoses were very rare. The prevailing type of follicle had 
a thick granulosa and was still solid or had only a small antrum. Small Graafian follicles were present and there were numerous primordial follicles around the periphery. No fragmenting ova were noted. There were no corpora lutea, but in some places the granulosa or part of it had begun an abnormal lutein transformation. A rat killed 9 days after discontinuation of treatment, at the age of 34 days, possessed a few good corpora lutea derived from the granulosa and more Graafian follicles than the 22 day rats. But the majority of the follicles was still in the secondary or tertiary stage. A few egg cells had fragmented. Mitoses were fairly numerous in the granulosa and not seen in the theca and interstitium. Follicles and corpora made up about two-thirds of the parenchyma. The theca was thin and mostly fibrous; the interstitium was predominantly in an epithelial form with a coarse nuclear structure.

Vaginal cycles after cessation of treatment were irregular, and four rats observed from the sixth to the tenth month showed permanent estrus.

Sex hormones. We have treated several litters of rats with estrogens and androgens as a basis of comparison of masculinizing and feminizing changes.

Twenty-two rats were given Amniotin Squibb on alternate days after the eighth day, four injections of ten and seven injections of 100 international units. Sixteen rats received ten injections of $0.32 \mathrm{mg}$. Perandren Ciba (testosterone acetate) and seventeen rats were given fourteen injections of $0.25 \mathrm{mg}$. Neohombreol Roche (testosterone propionate).

In the estrone injected rats the vagina opened by the seventeenth day and thereafter was cornified during treatment. Vagina and preputial glands became larger than in females of that age. The mammary ducts proliferated. Uteri and clitoris did not enlarge.

In one series of testosterone injected rats the vagina opened by the fourteenth day which is earlier than in the estrin series. Vaginal smears were diestric. With exception of the vagina, the female genital tract was infantile. A well defined ridge 
extended along the medial surface of the uterus. The enlargement of the clitoris surpassed that which was obtained with chorionic or mare serum hormone. The preputial glands enlarged and, as after mare serum hormone, the mammary acini attained full size, although the ducts were short. Rete and Wolffian body were prominent. In a subsequent series of testosterone treated rats the formation of the lower vagina was prevented in fourteen of sixteen rats. The conditions of treatment were the same in both series.

Prostates were found in one rat in each series treated with sex hormones. Both animals were 1 month old. Two other testosterone treated rats were searched for a prostate at the age of 6 weeks, but none was found. The prostate which had been exposed to the influence of female hormone was so large that it had been recognized macroscopically and was the only one recovered during this study with bilateral lobes. Histologically it was inactive. The prostate of the testosterone treated rat was large and fully active.

Two rats injected with female hormone were sacrificed when 30 days old. Four rats injected with male hormone were killed when 29 days old and two others on the forty-second day. The injection of estrin or androgen exerted the same effect on ovarian structure; and the ovaries from the older rats were not different from those of the younger ones. All the ovaries were small and composed of follicles arranged around a central mass of connective tissue with septa radiating into the follicular zone. Near the fimbria and ligament there was a great bulk of neogenic tissue (ovogenesis increases after hypophysectomy according to Swezy and Pencharz '32), and while intermediate stages were somewhat rare, Graafian follicles of various sizes occupied the entire peripheral zone. The granulosa of the Graafian follicles was very active, the thick wall often almost closed the antrum. There were also many follicles in which the granulosa cells had pycnotic nuclei and basophile droplets in the cytoplasm. In the two rats which had been treated with female hormone, follicular degeneration was especially marked. Fragmentation of ovocytes was so 
common in sex hormone injected rats that the number of polyovular follicles far surpassed what had been obtained in any other series.

Theca and interstitium were inhibited (fig. 15) and mitoses were rarely found. The theca was thin and usually fibrous. Diligent searching revealed small areas where it was composed of larger cells. Interstitial tissue was scanty and almost limited to the space between the large follicles around the ovarian periphery, and the cells were minute with small dark nuclei of the various shapes seen commonly in rats 11 to $\mathbf{1 5}$ days old. They were round, elongated or polygonal with coarsely distributed chromatin.

Lacassagne and Raynaud ('39) began treatment with testosterone on the first day of life and obtained an even greater depression of follicular development than occurred in our material. Salmon's observations ('38) on adult rabbits and monkeys parallel those on suckling rats, for he finds genital inhibition. The reports on adult rats and mice describe luteinization. Freed, Greenhill and Soskin ('38) obtained luteinization in adult rats with large doses and inhibition with small doses of testosterone propionate.

After cessation of treatment, vaginal cycles were prolonged in estrin injected rats; between the seventh and tenth month one out of five rats stayed in constant estrus and two in constant diestrus. Nineteen of tweny-two testosterone injected rats came into permanent estrus within 3 weeks after cessation of treatment.

\section{DISCUSSION}

The results of our study are in keeping with the general concept that normally the ovarian follicular hormone induces the estrus condition of the animal while the corpus luteum induces diestrus. In follicle cysts the theca often remains active and has an estrogenic function after the regression of the granulosa. It has been reported from many sources that ovaries in which the theca predominates, as in our experimental animals, or interstitial ovaries without follicles, main- 
tain constant vaginal cornification. Parkes ('24a) is the only author who states that interstitium consisting of small cells induces cyclic changes and luteinized interstitium a permanent diestrus. We observed permanent estrus throughout in rats with prominent theca or interstitium. That the cells are small in young and large in grown animals seems merely to make a quantitative difference in estrogenic activity since in the youngest rats not even the vaginal mucosa responded, while in puberal rats there was stimulation not only of the vaginal mucosa but also of the vaginal wall, uteri and mammary ducts. In one puberal rat the estric effect of the theca was strong enough to counteract the diestric influence of the corpora lutea which were present. Genther-Schmidt ('36) gave another example of the antagonism between lutein tissue from granulosa and from theca. She found that extensive theca luteinization during pregnancy resulted in abortion.

In deficient ovaries in which the follicles become atretic and fail to mature and transform into corpora lutea, lutein changes occur in theca or interstitium instead of the granulosa. Engle ('31) stated that the Aschheim Zondek reaction is not obtained in young mice before Graafian follicles have formed in the ovary. Selye and Collip ('33) studied the effect of prolonged administration of gonadotropic hormone from pregnancy urine on rats too young to give the Aschheim Zondek response. Their animals came in vaginal estrus which lasted through the time of injections. In the ovary there was a thecal hypertrophy while the maturation of follicles and the formation of corpora lutea was suppressed beyond the age of normal puberty. It depends on the stage of the treated animals whether pregnancy urine produces lutein transformation of the theca or the granulosa. The relationship between follicles and theca-interstitium in the female parallels the relation between tubules and Leydig cells in the male; an excess of interstitium indicates some kind of impairment in the germinative tissue. While in the male the interstitium and germinative tissue are as different in morphology as in function, in 
the female the luteinized cells from the ovarian theca look much like luteinized granulosa cells.

Bradbury and Gaensbauer, repeating. Selye and Collip's experiment, confirmed their findings of continuous estrus and in addition observed signs of masculinization. Different authors have reported instances of a masculinizing action of gonadotropic hormones without mentioning the persistent estrus which we now must assume was present. Pfeiffer ('36), performing various kinds of gonad transplantation, realized that permanent estrus and masculinization were an entity. He explained the condition by a shift in the relationship between gonad and hypophysis. Hill ('37) observed similar phenomena in rats with an ovary transplanted to the ear and believed that the exposure of the ovary to a temperature lower than that of the abdominal cavity changed its endocrine function. But Deanesly found the age of the graft to be the important factor rather than the temperature of its environment. Theca luteinization in the transplanted ovaries was described by both Hill and Deanesly.

Masculinization of females by the administration of gonadotropic substances has been recorded in several species: fowl (Uhl and Engelbreth-Holm, '37; Domm, '37; Uotila, '39), guinea pigs (Papanicolau and Falk, '34; Guyénot and NavilleTrolliet, '36) and mice (Greene, Burrill and Ivy, '38, '39). The ovaries of masculinized mammals were lacking in corpora lutea, but they contained an excessive mass of thecal or interstitial tissue, usually in the luteinized form. In the course of our experiments, the first signs of masculinization were noted early, often in 10 day old rats. Some days later the vaginal membrane ruptured, but the rest of the female genital tract remained infantile. Vaginal opening is a doubtful estrogenic sign, for it can be induced equally well with androgen, (Rubinstein, Abarbanel and Nader, ('38) and our own experience). On the other hand, the formation of the caudal vagina may also be inhibited by either the male hormone (Hamilton and Gardner, '37; Raynaud, '38 a, b, c) or the female hormone (Greene, Burrill and Ivy, '39). 
The enlargement of the Wolffian body we consider a result rather than the source of intersexuality. Male Leydig cells were not seen and occasional tubules in the cortex homologous to seminiferous tubules were too inconspicuous to exert much endocrine influence. The regular change in ovarian architecture was the great increase of thecal or interstitial tissue. The lack of corpora lutea long after discontinuation of treatment indicates a basic disturbance in ovarian function. It is noteworthy that during the period of androgenic function the theca and interstitium were not luteinized in many cases. From the response of the accessory organs we must conclude that these small, morphologically immature cells secrete male hormone and perhaps female hormone too. The stimulation of male and female organs was more marked, after the cells had reached an intermediate stage. In rats with fully luteinized theca and interstitium and pronounced estric symptoms, however, the androgenic effect was no longer apparent and could be detected only by special means.

\section{SUMMARY}

In suckling rats, gonadotropic preparations produced follicular atresia, theca hypertrophy, vaginal rupture and hypertrophy and certain symptoms of masculinization such as penis-like differentiation of the clitoris. When the masculinizing effect became apparent, the follicles were less numerous, but had acquired a thick theca. With advancing age of the injected rats there appeared more or less numerous follicle cysts, and the ovary and the entire female genital tract hypertrophied. Theca and interstitium were luteinized earlier than the granulosa. During the period of preponderant thecal luteinization the vagina became cornified. After the luteinized theca had regressed and corpora lutea had become prominent, vaginal cycles occurred. The relation between interstitial proliferation, interstitial luteinization and follicle stimulation varied with the gonadotropic agent employed. It is apparent that when the ovary is incapable of undergoing corpus luteum formation under gonadotropic stimulation, it may produce 
enough androgenic substance to cause a marked masculinization.

In suckling rats injected with estrin the vagina opened precociously and stayed cornified. In rats injected with testosterone the opening occurred even earlier but the mucosa consisted of nucleated cells and the male homologues hypertrophied. Either hormone caused increased development and atresia of follicles, proliferation of primary follicles and atrophy of the interstitium.

After the injections of small doses of gonadotropic material or of sex hormones were discontinued, the rats recovered at least temporarily. The vaginal estrus was prolonged or permanent after withdrawal of higher doses. Following moderate doses of chorionic hormone, the stage of permanent estrus was preceded by a period of vaginal cycles. The ovaries of adult females in permanent estrus were devoid of corpora lutea.

\section{ACKNOWLEDGMENTS}

We are indebted to the Winthrop Chemical Company for a supply of Korotron, the Upjohn Company for the Gonadogen and Chappel Brothers for the Prephysin used in this investigation. The Amniotin was furnished by E. R. Squibb and Sons and the Neohombreol by Roche-Organon Ine.

\section{LITERATURE CITED}

ALLEN, E. 1923 Ovogenesis during sexual maturity. Am. J. Anat., vol. 32, pp. 439-482.

Bradbury, J. T. and F. Gaznsadure 1939 Maseulinization of the female rat by gonadotropic extracts. Proc. Soc. Exper. Biol. and. Med., vol. 41, pp. 128-131.

Brambeli, R., A. S. Parkes and U. Fielding Changes in the ovary of the mouse following exposure to $\mathrm{x}$-rays.

1927 a I. Irradiation at three weeks old. Proc. Roy. Soc. London, Series B, vol. 101, pp. 29-56.

$1927 \mathrm{~b}$ II. Irradiation at or before birth. Proc. Roy. Soc. London, Series B, vol. 101, pp. 95-114.

$1927 \mathrm{e}$ III. Irradiation of the non-parous adult. Proc. Roy. Soc. London, Series B, vol. 101, pp. 316-328.

1928 IV. The corpus luteum in the sterilized ovary and some eoncluding experiments. Proe. Roy. Soe. London, Series B, vol. 102, pp. 385-396. 
DEANESLY, R. 1939 Audrogenie aetion of ovarian grafts. J. Physiol., vol. 92, pp. 34-35.

JoN N, I. V. 1937 Observations concerning anterior pituitary-gonadal relations in the fowl. Cold Spring Harbor Symposia on Quantitative Biology, vol. 5, ip. 241-257.

ENGLE, E. T. 1931 Prepuberal growth of the ovirian follicle of the albino mouse. Anat. Ree., vol. 48, p. 341.

Fraed, S. C., J. P. Greenhilu and S. Soskin 1938 Diphasie effect of male sex hormone on the pituitary of the female rat. Proc. Soe. Exper. Biol. and Med., vol. 39, pl. 440-442.

Gafinsbauhr, F., and J. T. Bradbury 1939 Comparative potency of eommercial anterior pituitary-like proparations. Endocrinol., vol. 24, pp. 867-871.

GENTHER-SOHMIDT, I. 1936 The excretion of theelin in the urine of guinea pigs with irradiated ovaries. Anat. Rec., vol. 64, pp. 255-266.

Greme, R., M. W. BurRIll AND A. C. Ivy 1938 The experimental production of intersexuality in the female rat. Am. J. Ob. and Gyne., vol. 36, pp. 1038-1046.

1939 Experimental intersexuality. The paradoxical effects of estrogens on the fmale rat. Anat. Rec., vol. 74, pp. 429-438.

GRFFNr, R. R., AND M. W. BURRILL 1939 Experimental intersexuality; maseulinization of female rats by post-partum treatment with anterior pituitary-like hormone. Proc. Soe. Exper. Biol. and Med., vol. 40, pp. 514-516.

Guyénot, E. ANd Mare. Naviste-Trolliet 1936 Maseulinization provoquée de femelles de cobaye (Extraits hypophysaires et urine de femme enceinte) Revue Suisse de Zool., vol. 43, pp. 415-454.

Hamilton, J. B., AND W. U. GarDNeR 1937 Effects in female young born of pregnant rats injected with audrogens. Proe. Soc. Kxper. Biol. and Med., vol. 37, pp. 570-572.

HILL, R. T. 1937 Ovaries secrete male hormone. I. Restoration of the castrate type of seminal vesieles and prostate glands by grafts of ovaries in mice. Endocrinol, vol. 21, pp. 495-502.

LACASSAGNE, A., AND A. RAYNACD 1939 Effets, sur la souris, d'injections longtemps répétées de propionate de testosterone. Compt. rend. Soe. de biol. T, 130, pp. 689-693.

Papantcolat, G. N. and H. A. Falk 1934 Action of pregnancy urine extract (Follutin) on the external genitalia of female guinea pigs. Proe. Soe. Exper. Biol. and Med., vol. 31, pp. 750-751.

Parkes, A. S. On the occurrence of the oestrous eycle after $x$-ray sterilization. 1926 I. Irradiation of mice at three weeks old. Proc. Roy. Soc. London, Series B, vol. 100, pp. 172-199.

1927 a II. Irradiation at or before birth. Proc. Roy. Soe. London, Series B, vol, 101, pp. 71-94.

$1927 \mathrm{~b}$ III. The periodieity of estrus after sterilization of the adult. Proc. Roy. Soc. London, Series B, vol. 101, pp. 421-449.

1927 e IV. Irradiation of the adult during pregnancy and lactation; and general summary. Proe. Roy. Soc. London, Series B, vol. 102, pp. 51-62. 
Preifrer, C. A. 1936 Sexual differences of the hypophysis and their determination by the gonads. Am. J. Physiol., vol. 58, pp. 195-226.

PRICF, D. 1937 Rat prostate and seminal vesiele grafts in relation to the sex and sex hormone state of the host. Anat. Ree, vol. 70, pp. 60-61 suppl.

R.aynatid, A. 1938 a Evolution du tractus génital mâle eliez les souris femelles intersexuées ne reçevant pas d'injection d'hormone mâle après la naissance. Compt. rend. Soc. de Biol., T. 119, pp. 632-637.

1938 b Etude de l'appareil génital femmelle des souris intersexuées n'ayant pas reçu d'injection d'hormone mâle après la naissance. Compt. rend. Soc. de Biol., T. 119, pp. 637-640.

1938 c Développement et différentiation des diverses parties du tractus génital mâle des souris femelles intersexuées reçevant après la naissance des injections de propionate de testosterone. Compt. Rend. Soc. de Biol. vol. 119, pp. 1033-1038.

Rubinstein, H. S., A. R. Abarbant and S. N. Nader 1938 Influence of testosterone propionate on vaginal opening in the immature albino rat. Proc. Soc. Exper. Biol. and Med., vol. 39, pp. 440-442.

Salmon, U.J. 1938 The effect of testosterone propionate on the genital tract of the immature female rat. Endocrinol., vol. 23, pp. 778-783.

Seliye, H., ANd J. B. Corstip 1933 Production of exelusive thecal luteinization and continuous estrous with anterior-pituitary-like hormone. Proc. Soc. Exp. Biol. and Med., vol. 30, pp. 647-649.

Soвотта, J. 1895 Über die Bildung des corpus luteum bei der Maus. Anat. Anz. Bd. 10 , S. $482-490$.

Swhzy, O., ANd R. Pencharz 1932 The ovary of the rat after hypophysectomy. Abstracted in Anat. Ree., vol. 54, p. 48. Suppl.

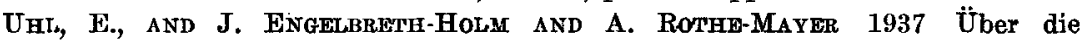
Wirkung gonadotropen Hormons (Antex Leo) auf das Kammwachstum bei Hennen. Endokrinologie, B. 18, S. 242-250.

UOTIIA, U. 1939 The maseulinizing effect of some gonadotropic hormones on pullets compared with spontaneous ovariogenic virilism. Anat. Rec., vol. 74 , pp. $165-188$.

Witschi, F., J. J. Mahoney and G. M. RILEY 1938 Occurrence of prostatic lobes in the female rat. Biol. Zent., Bd. 58, S. 455-464. 


\section{PLATES}




\section{PLATE 1}

\section{EXPLANATION OF FIGURES}

High power photographs were made with the Zeiss fluorite immersion $\times 100$ and compensation eyepiece 7 .

1 Theca tissue of 15 day old control.

2 Section from the ovary of an untreated, 31 day old rat. Magnification $\times 20$.

3 Theca-interstitium of the ovary of figure 2.

4 Hyperplastic, epithelial, interstitium of the ovary of figure 6.

5 Hypertrophic theca in 15 day old rat, treated from the sixth day on with 2 units APL. Maseulinization apparent and female organs infantile.

6 Section from the ovary of a 34 day old rat, treated from the sixth day on with 2 units APL. The animal was moderately masculinized; the female organs were infantile. Magnification $\times 20$.

7 More peripheral seetion through the same ovary as figure 6. Primary follicles are seen radiating out under the ovarian surface from the depression. magnifieation $\times 31$.

8 Degenerating follicle of another 34 day old rat treated with 2 units APL from tho sixtl day on. The basement membrane between granulosa and theca has disappeared. The female and male genitalia were hypertrophic. 
LORE MARX AND J. T. BRADBURY
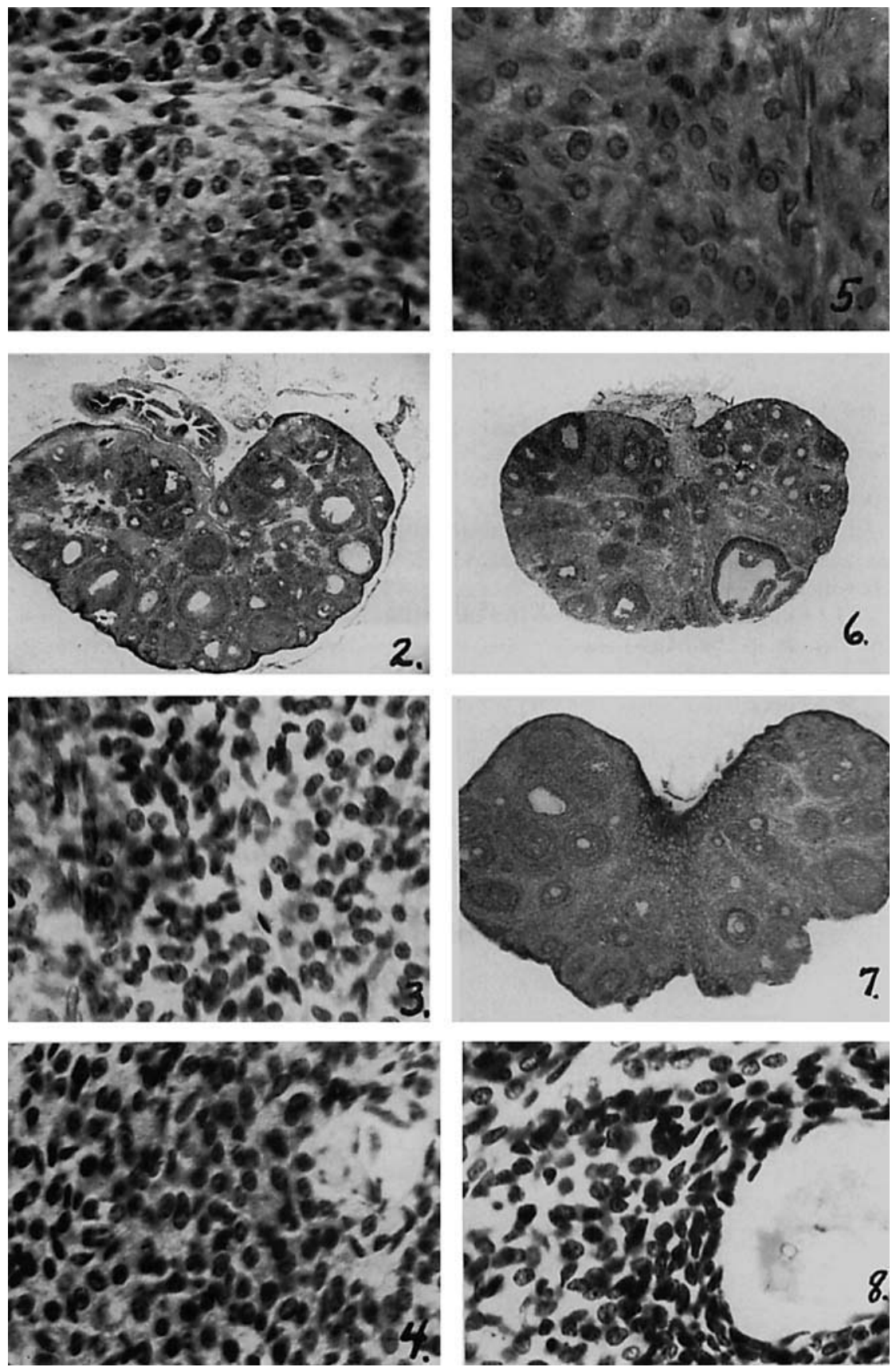


\section{PLATE 2}

\section{EXPLANATION OF FIGURES}

9 Granulosa lutein tissue of a 51 day old rat, treated with 5 units APL from the sixth day.

10 Margin of corpus luteum in untreated, 10 week old rat. The lutein tissue is surrounded by a thin, fibrous theca. Outside there is epithelial interstitium remaining from atretic follicles.

11 Luteinized theea and interstitium in the less hypertrophic pair of ovaries of two 23 day old rats, treated from the sixth day on with 0.5 units pregnant mare serum extract. The female and male genitals were very hypertrophic.

12 Theca lutein tissue of ovary of figure 9.

13 Luteinized interstitium enclosing the remainder of a follicle of a 47 day old rat, treated from the sixth day on with 10 units APL. The lutein cells are larger than in rats injected with 5 units APL, figure 12.

14 Slightly luteinized theca in the smaller pair of ovaries of two 23 day old rats, treated from the sixth day on with 5 units prephysin. The genital apparatus was infantile.

15 Fibrous theca and small interstitial cells in a 30 day old rat, injected from the eighth day on on alternate days with 10 international units amniotin. 
LORB MARX AND J T BRADBLRY
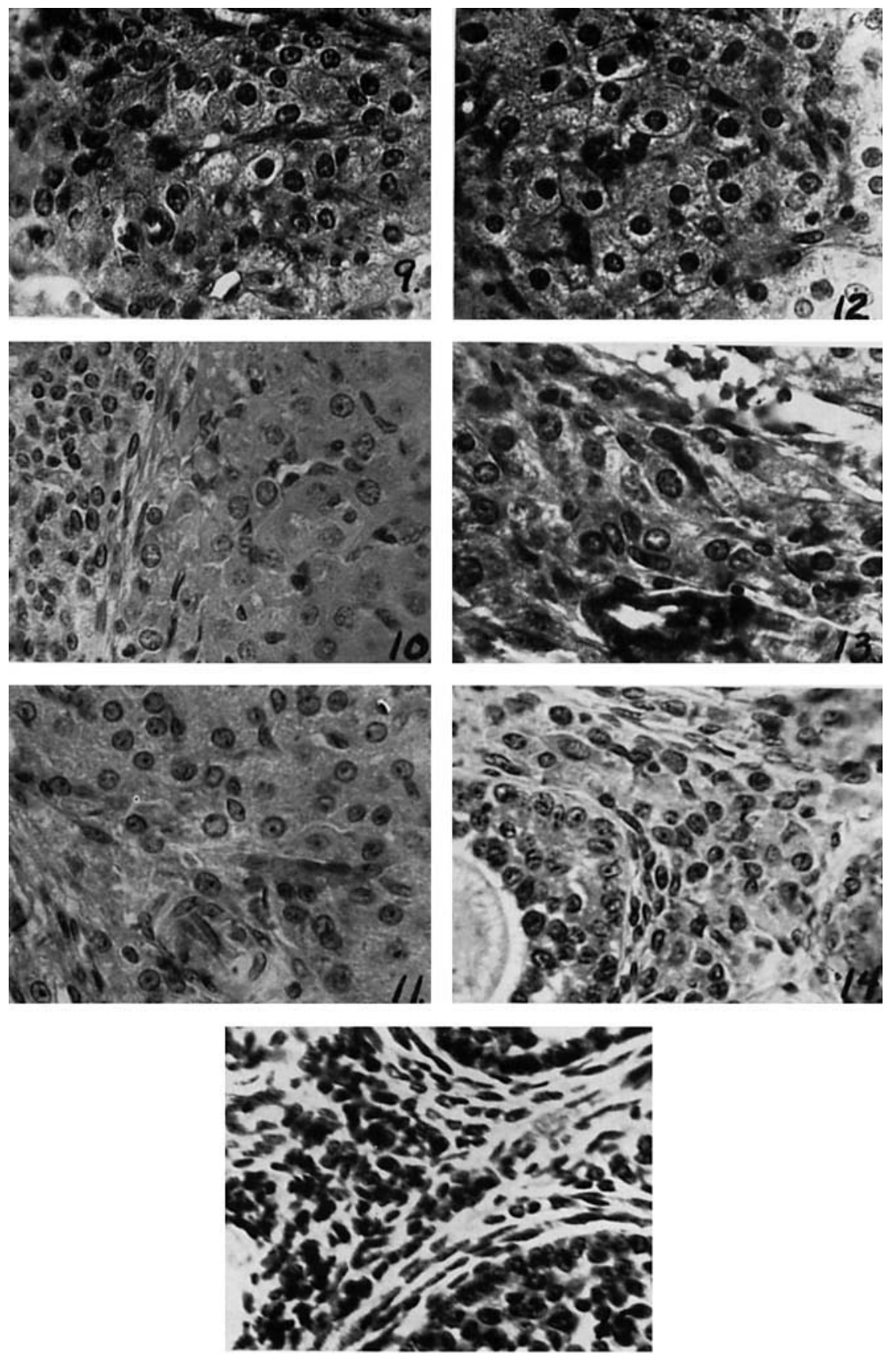